\title{
Electrical drive and control of an electric motor step by step by step bipolar
}

\author{
Violeta Ciucur $^{1}$ \\ ${ }^{1}$ Constanta Maritime University, Faculty of Naval Electro-Mechanics, 104 Mircea cel Batran Street, 900663, Constanta, \\ Romania, e-mail address: violeta.ciucur@cmu-edu.eu
}

\begin{abstract}
PWM, (Pulse Width Modulation) is the most effective way to control analog circuits using numerical outputs by changing the duration and frequency of the signal.

The duration of each state $t_{1}$ and $t_{2}$, so the filling factor, where $T=t_{1}+t_{2}=$ constant.

If only one of the times $\left(t_{1}\right.$ or $\left.t_{2}\right)$ varies, then the $T t$ period of a cycle varies, so the $f=1 / \mathrm{T}$ frequency varies.

The PWM signal is actually a modulated rectangular signal over the duration by modifying the duration of each period $\mathrm{t}_{1}, \mathrm{t}_{2}$ of the cycle as well as the change in frequency.

The maximum benefit of a stepper motor can only be obtained if it is ordered correctly, this requiring a direct current source, an electronic switch and a controlled pulse generator (numerical information).

The frequency of the CLOCK cycle is measured in $\mathrm{Hz}$ and the filling factor is measured in percentage (\%).

The amplitude of the output signal is constant even if the amplitude of signals producing the fill factor varies.
\end{abstract}

Key words: stepper engine, signal, bipolar, power, CLOCK

\section{INTRODUCTION}

Step-by-step engines are used in microcontroller applications.

An engine can be ordered by a direct microcontroller and through specialized, programmable interfaces.

Step by step engine is controlled by Step \& Direction orders by principal controller and it is suitable for systems with many axes.

A digital tracker module allows tracking an analogical external signal and complete definition of parameters.

\section{CONFIGURATION PARAMETERS FOR UNITY} -the pass,

Configuration parameters for unity:

-current,

-internal ramp,

-type of functioning "

You can get the following functions:

- report settings between reference speed and speed of the engine (transmission road);

- to set scala maximum of analogical reference $(0 \div 10 \mathrm{~V}$ or $-10 \mathrm{~V} \div 10 \mathrm{~V}$ ); -activate / disable for feedback for position and speed (open loop / closed loop);

-to set a type for follow.

Step-by-step engines are used where high precision is required (hard disk, copiers, printers).

Step-by-step engines are limited to situations where large power is required (usual powers between microwaves and kilowatts).

Step-by-step engines are used in small power applications, characterized by fast, accurate, repeatable movements: XY plotting, flexible disk drives, moving printing head to printers, actuating robot orientation mechanisms, axial movement of systems elements Optics, 2D positioning tables, for drilling machines, etc.

The engine control is made electronically and motor displacements can be obtained depending on the control program.

Theoretically step by step is built very simply.

Has no brushes or contacts.

Essentially, it is a synchronous engine whose electromagnetic field is switched electronically to move the motor rotor.

The step-by-step electric motor is an electromagnetic converter that performs the conversion of control pulses applied to the motor phases into a rotation motion consisting of discrete angular displacements of equal size and represents the steps of the engine. 
The number of steps must correspond, in the case of correct officials, with the control pulse number applied to the engine windings.

\section{ELECTRICAL DRIVE AND CONTROL OF AN ELECTRIC MOTOR STEP BY STEP BY STEP BIPOLAR}

When the stator phases are fed, magnetic fields are generated, interacting with permanent magnet flows, giving rise to forces couples, moving the rotor.

Ordering aspects in sequences, simple, double and mixed, are similar to MPP with variable reluctance.

Instead, to the extent that the rotor performs a number of steps and the southern pole of the rotor approaches the Pole A 'of the stator, the current by winding the $\mathrm{AA}^{\prime}$ must change its meaning to oppose it a north pole and maintains the meaning of torque of forces.

Phase power is made with alternate polarity impulses, which complicates the control device structure, called the bipolar command.

The angular steps obtained are high (between $45^{\circ}$ and $120^{\circ}$ ), as the number of permanent magnets that may be disposed along the rotor circumference is much lower than the number of teeth accessible for the step motor step by step with variable reluctance.

A solution that eliminates the disadvantage of a small step angle is that of a step-by-step motor.

A step-by-step hybrid engine is a combination of the first two types, combining the advantages of both and being the step-by-step motor used in the vast majority of applications.

The rotor consists of a permanent, longitudinally disposed magnet, at whose extremities two toothed crown of ferromagnetic material are fixed.

The teeth of a crown constitute the North Poles, and the teeth of the other crowns, South Poles.

The teeth of the two crowns are spatially offset so that if a tooth of a crown is located next to a steadier tooth, the rotor tooth on the other crown is halfway between two steadied teeth.

Step by step engine is a category of synchronous machine, characterized by a construction and a power system suitable for discrete operation, that is, "in steps".

For step-by-step motor control can be used integrated circuits together with a CLOCK generator.

Integrated control assembly generates control signals for double stator motor and allows for selecting direction and the execution of a whole step or half step, by properly programming its inputs.

The circuit is connected as an unstable circuit and the condenser is loaded from the supply voltage by the two resistors $R_{1}$ and $R_{2}$.

The discharge pin noted with 7 is connected outside to the junction between the two resistors.

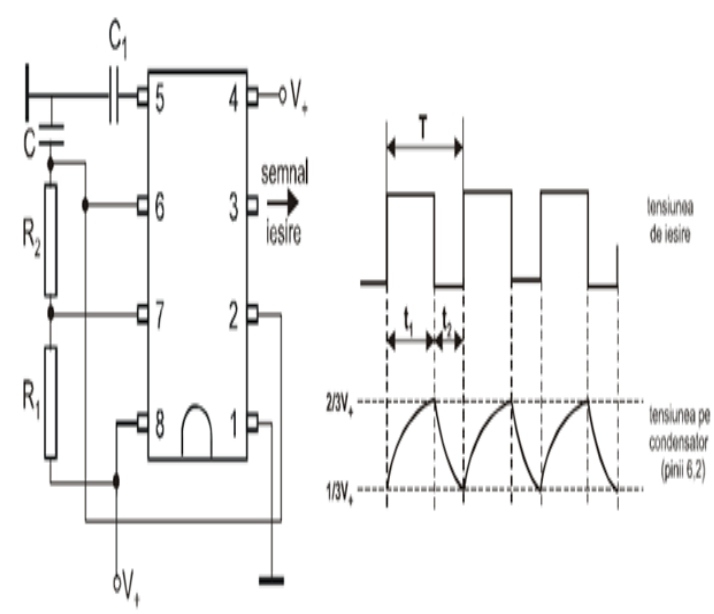

Figure 1 Unequable module

The supply voltage is $4.5-18 \mathrm{~V}$, the power supply is 3-6 mA and time of growth / decrease time: $100 \mathrm{~ns}$.

To express the evolution in time of the signal CLOCK, the sizes can be calculated, the time period when the clock signal is at $5 \mathrm{~V}$, called and logically 1 $\left(t_{H}\right)$, the time period when the CLOCK signal is at $0 \mathrm{~V}$, called and logically $0-\left(t_{L}\right)$, period, equal to the sum of periods $t_{H}$ și $t_{L}-(T)$ and frequency (f):

$$
\begin{array}{r}
H=0,693 *\left(R_{2}+2 * R V_{2}\right) * C_{6} * 10^{3}=0,693 * \\
(5000+3150) * 0,15 * 10^{-6} * 10^{3}=0,847 \mathrm{~ms} \quad(1) \\
{ }_{L}=0,693 * R V_{2} * C_{6} * 10^{3}=0,693 * 3150 * 0,15 * \\
10^{-6} * 10^{3}=0,327 \mathrm{~ms} \quad(2) \\
\boldsymbol{T}={ }_{H}+{ }_{L}=0,847+0,327=1,174 \mathrm{~ms}(3) \\
\boldsymbol{f}=\frac{1,44}{\left(R_{2}+2 * R V_{2}\right) * C_{6}}=\frac{1,44}{(5000+2 * 3150) * 0,15 * 10^{-6}}=849,55 \mathrm{~Hz}
\end{array}
$$

\section{RESULTS}

Using equations (1), (2), (3) and (4), can obtain the values of:

$$
\begin{gathered}
R_{2}=5 \mathrm{k} \Omega ; \\
R V_{2}=3 \mathrm{k} \Omega ; \\
C_{6}=0,22 \mu \mathrm{F} .
\end{gathered}
$$

The $12 \mathrm{~V}$ power source contains a voltage regulator to ensure the stresses required for the power and command storey.

The voltage controller will provide the $5 \mathrm{~V}$ voltage required by the control storey, being a 3-pin integrated circuit. 
Journal of Marine technology and Environment

Electric characteristics are: current at exit $2 \mathrm{~A}$, output voltage of $5,6,8,12,15,24 \mathrm{~V}$, high temperature protection and protection against short circuit.

An oscillating signal is generated, stair type through pin 3 where is connected a diode to monitor a signal.

The integrated circuit is the translator to generate matching sequences for operations like "half step", "one-phase-on full step" and "two-phase-on full step".

This block is controlled with two inputs: direction (CW/CCW) and module (HALF/FULL) and forward a code in 8 steps, thus generating the 4 signals to output.

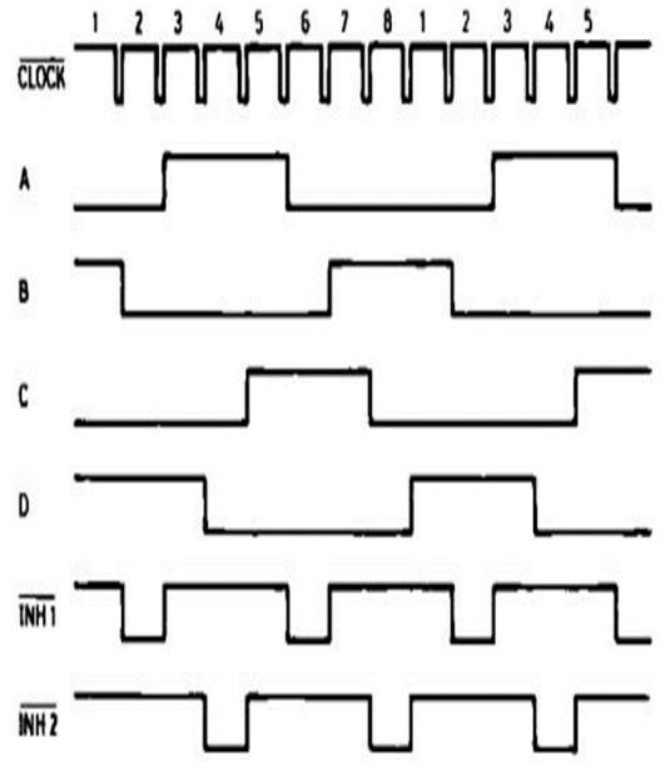

Figure 2 Half-Step signal

This phase of the engine corresponds directly with the "'Half-Step" mode and the signal oscillation is in the figure.

By selection "High Level" on "Half/Full" generate two other signals INH1 and INH2.

These signals have the role of rushing the current dissipation process when a winding stops of MPP.

The signal "Full-Step" is obtained by jumping over certain steps in the 8-step sequence when this mode is selected, the Half / Full input is low.
Year 2021, Vol.II

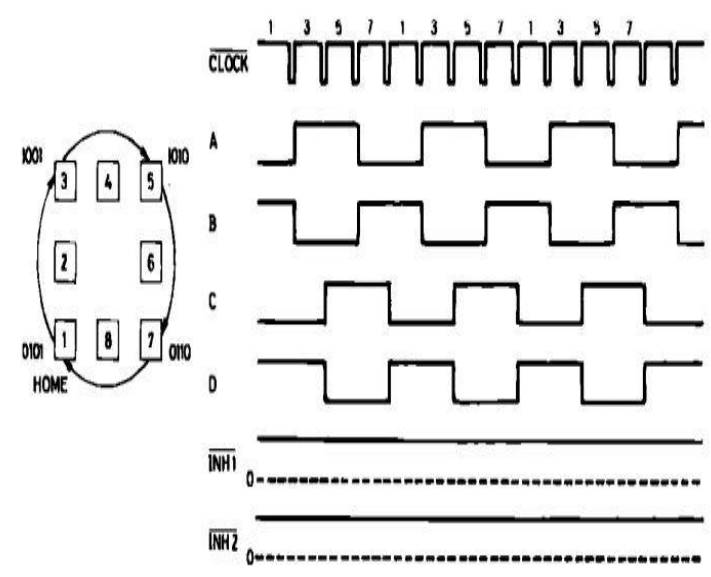

Figure 3 Full-step signal (two-phase-on)

By selecting "Full step" mode When the translator transmits a para sequence generates two other inh1 and in signals who have the role of hurrying the current dissipation process when a winding of MPP stops.

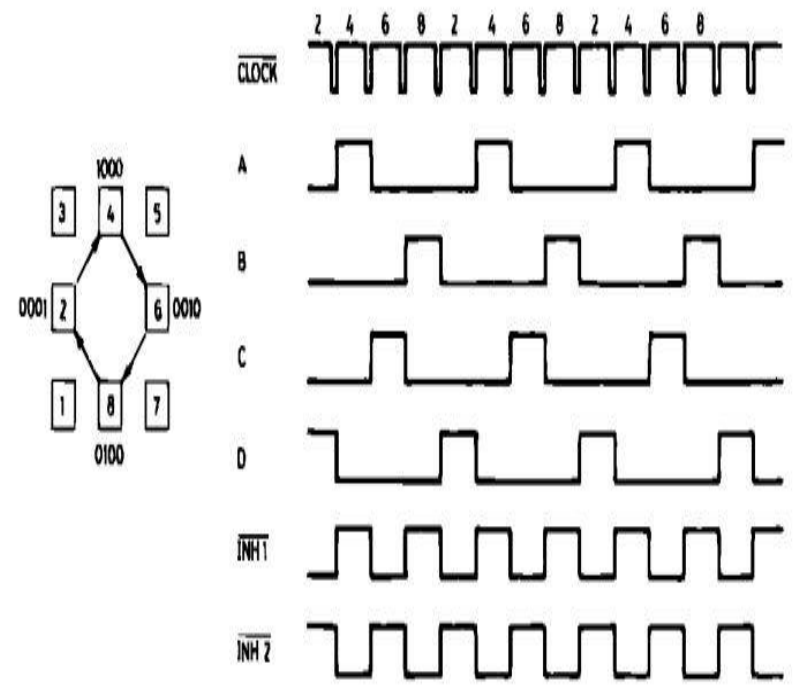

Figure 4 Full-step signal (one-phase-on)

The system is powered by a source of $12 \mathrm{~V}$ what uses a voltage stabilizer to adjust the required voltage of 5-12 V with 2A per phase.

The paper addresses the command and supply of motors step by step because, in fact, these areas are inseparable.

Step-by-step motor compatibility with numerical calculation technique has led to superior performance in the positioning process, which has led to the extension of their areas of applicability [7]. 


\section{DOI. 10.53464/JMTE.02.2021.02}

\section{Journal of Marine technology and Environment}

\section{CONCLUSIONS}

Step-by-step engines are used in situations where large powers are not required and secure in the field of work, starts, stops and sudden reversals without loss of information, namely omissions of steps.

Characteristics of fast, accurate and repeatable movements make the motor step by step the right candidate for small power applications such as: positioning tables $2 \mathrm{D}$, drilling machines, the operation of robot orientation and pressure mechanisms, moving the printing head to printers, plotter $\mathrm{x}-\mathrm{y}$ etc.

Step-by-step engine is an electromechanical converter that makes the transformation of a digital pulse train into a proportional movement of its axis

The rotor's freaking of step-by-step engine consists of discreet, successive angular displacements of equal sizes and representing the steps of the engine.

The step-by-step engine also shows the property of being able to enter synchronicity to the command impulses even from the rest state, operating without sliding, and the braking is also carried out without the output of synchronism.

Due to this, it is ensured, shortages and sudden reversals without any loss of steps.

The speed of a step-by-step engine can be adjusted within wide limits by changing the frequency of input pulses.

Thus, if the angular step of the engine is $1.8^{\circ}$ the number of impulses necessary for a complete rotation is 200 , and for an input signal with the 400 pulse frequency per second, the engine speed is 120 rotations per minute.

\section{ACKNOWLEDGMENTS}

This integrated generates control signals for the Double Stator engine and allows the selection of the travel direction and the execution of a whole step or half step by properly programming its inputs.

Trying to speed up a load too fast when the stepper motor cannot generate enough torque to move to the next step before the next pulse unit will lead to a jumped step and a loss in position.

Most stepper motors are bidirectional and allow fast acceleration, stopping and reversing without loss of steps, if they are controlled with a frequency lower than the limit frequency corresponding to the respective operating mode.

In order to extend the operation of stepper motors at speeds higher than the speed corresponding to the limit frequency, it is necessary to accelerate by gradually increasing the frequency of the control pulses.

The presented driver is simple to be made practically having a low cost of components

Due to the versatility that proves both from the point of view of the movement and speed, it is the ideal

\section{Year 2021, Vol.II}

candidate for applications such as scanner, fax, moving the printing head to printers, X-Y plotters.

One of the system's disadvantages is the lack of automation in motion movement step by step.

It can not automatically adjust the movement parameters: speed, sense, speed, etc.

The practical design and implementation of such modern drive systems are a difficult task, as it involves knowledge from several distinct areas (theoretical research, complex mathematical operations, electric drives, electric machines, digital and industrial electronics, system control, numerical systems Hardware and software, Visual $\mathrm{C}++$ programming).

The paper addresses the command and supply of motors step by step because, in fact, these areas are inseparable.

The compatibility of the step-by-step engine with a numerical calculation technique has led to superior performance in the positioning process, which has led to the expansion of the areas of applicability.

\section{REFERENCES}

[1] Alexandru Morar, 2002, Echipamente de comandă a motoarelor pas cu pas implementate pe calculatoare personale (Stepper motor control equipment deployed on personal computers), „Petru Maior”Publishing House University, Târgu - Mureş, Romania.

[2]Alexandru Morar, 2007, Comanda inteligentă a acţionărilor electrice cu motoare pas cu pas (Intelligent control of electric drives with stepper motors) Mediamira Publishing House, Cluj-Napoca, Romania.

[3]Kelemen A., Crivii M., 1982, Motoare electrice pas cu pas (Stepper electric motors), Technical Publishing House, Bucharest, Romania.

[4] Liviu Negrescu, 2001, Limbajele C şi C++ pentru începători ( $\mathrm{C}$ and $\mathrm{C}++$ languages for beginners), MicroInformatica Publishing House, Cluj-Napoca, Romania.

[5] Jon Bates, Tim Tompkin, 2001, Utilizare Visual $C++6$, (Using Visual $C++6$ ), Teora Publishing House, Bucharest, Romania.

[6] Cristian George Savu, 1998, Ghidul programatorului Visual C++ 5.0 (Visual C ++ 5.0 Developer's Guide), Alleducational Publishing House, Bucharest, Romania.

[7] Samoilescu Gheorghe, Marin Georgiana, 2015, The analysis of short-circuit currents in a naval electrical network by means of software tools, Journal of marine Technology and Environment, vol.II, pp 71-78, Nautica publishing House, Constanta, Romania. 